\title{
Floods on Mars Released from Groundwater by Impact
}

\author{
Chi-yuen Wang, Michael Manga and Alex Wong \\ Department of Earth and Planetary Science \\ University of California, Berkeley CA 94720
}

On earth, large earthquakes commonly cause saturated soils to liquefy and streamflow to increase. We suggest that meteoritic impacts on Mars may have repeatedly caused similar liquefaction to enable violent eruption of groundwater. The amount of erupted water may be comparable to that required to produce catastrophic floods and to form outflow channels.

Key words: liquefaction, impacts, chaos 


\section{Introduction}

Liquefaction frequently occurs on Earth during or immediately after large earthquakes, when saturated soils lose their shear resistance, become fluid-like, and are ejected to the surface, causing lateral spreading of ground and foundering of engineered foundations (e.g., Terzaghi et al., 1996). During the 1964 Alaskan earthquake, for example, ejection of fluidized sediments occurred at distances more than $400 \mathrm{~km}$ from the epicenter (Waller, 1968). Increased streamflow is also commonly observed after earthquakes (Montgomery and Manga, 2003). Suggested causes include coseismic liquefaction (Manga et al., 2003), coseismic strain (Muir-Wood and King, 1993), enhanced permeability (Rojstaczer et al., 1995) and rupturing of hydrothermal reservoirs (Wang et al., 2004a).

Extensive laboratory and field studies (e.g., Terzaghi et al., 1996) show that saturated soils liquefy during ground shaking as a result of pore-pressure buildup that in turn is due to the compaction of soils in an undrained condition. Furthermore, laboratory experiments (Dobry, 1985; Vucetic, 1994) showed that the threshold of pore-pressure buildup is insensitive to the type of soils (from clays to loose sand) and the environmental conditions. Thus we may reasonably suggest that saturated soils on Mars, even though composed of pulverized basalt rather than alluvial sand, may also experience undrained consolidation, pore-pressure buildup and liquefaction when subjected to strong ground shaking.

Liquefaction caused by meteoritic impact is also preserved in the sedimentary record (Underwood, 1976; Warme et al., 1998; Terry et al., 2001). Among the documented examples is a field of circular plugs of sandstone near the Oasis impact crater in Libya, which "appear to be the result of upward movement of fluidized sand" (Underwood, 1976). Strong evidences for liquefaction (Terry et al., 2001) and related landslides (Bralower et al., 1998; Klaus et al., 2000) were also found shallow submarine sediments in connection with the Chicxulub impact at the Cretaceous-Tertiary boundary. Soil liquefaction during underground and surface explosions has also been documented (e.g., Charlie et al., 1996). Could meteoritic impact on Mars also have 
caused liquefaction and floods?

Heavy meteoritic bombardment on the early Mars formed a thick layer of dust, regolith and ejecta. Assuming that abundant water was present on the early Mars, a saturated aquifer of global extent may have been present beneath a few km of frozen ground (e.g., Carr, 1996;

Clifford and Parker, 2001). Stewart et al. (2003) showed that meteoritic impacts may cause melting and vaporization of ice in the ground close to the crater. We suggest here that liquefaction can release water at great distances from the impact site. Given that Mars' surface heat flow in the late-Naochian to early Hesperian was $\sim 5$ times greater than its present value (e.g., Schubert et al., 1992), it is likely that the cryosphere was much thinner, and thus much weaker, during that time (Clifford and Parker, 2003). Under these conditions, meteoritic impact may have caused widespread liquefaction of the near-surface aquifers (Clifford, 1997).

Unfortunately, quantitative studies of impact-induced liquefaction are limited. Leyva and Clifford (1993) calculated the pore-pressure change on Mars during an impact by assuming that the change was caused by a single compressional wave. Field and laboratory studies show, however, that pore-pressure change and liquefaction are more likely to be caused by many cycles of shearing of saturated soils (e.g., Terzaghi et al., 1996). In view of the difficulties in making theoretical predictions, we adopt an empirical approach.

\section{Relationship between crater size and spatial extent of liquefaction}

Because liquefaction is a major concern in earthquake-prone areas, numerous attempts have been made to predict its occurrence. Field and laboratory studies show that liquefaction depends on many factors, including earthquake magnitude, peak ground velocity, liquefaction susceptibility of soils, basin structures, and depth to the groundwater table (e.g., Terzaghi et al., 1996). Consequently, the occurrence of liquefaction is difficult to predict either physically or numerically; and empirical approaches, as a rule, have been adopted. The most used methods in engineering practice are the ground penetration tests for evaluating the liquefaction resistance of 
soils. Because of the required time and costs, such tests are mostly limited to sites of engineering importance.

In areas where such tests are absent, a simpler approach has been attempted (Kuribayashi and Tatsuoka, 1975; Ambraseys, 1988; Galli, 2000). Field observations show that, for earthquakes of a given magnitude $M$, the occurrence of liquefaction is mostly confined within a particular distance from the epicenter, i.e., the liquefaction limit, $R_{\max }$, beyond which liquefaction is not observed. The liquefaction sites at the farthest distance are those with optimal conditions for liquefaction. Figure 1a shows the relationship between earthquake magnitude and the distance between the hypocenters of earthquakes and sites of liquefaction. The compilation of observations in Figure 1a is based on eartlier compilations (Kuribayashi and Tatsuoka, 1975; Ambraseys, 1988; Galli, 2000) and updated with observations for 14 additional large earthquakes up to December, 2003 (Table 1). Based on the observations in Figure 1a, we obtain the following relation for the liquefaction limit:

$$
M=-5.0+2.26 \log R_{\max }
$$

where $R_{\max }$ is in meters. This equation is well constrained by data at earthquake magnitudes between 5.5 and 7.5 (Figure 1a), but becomes less constrained at $M>7.5$ because too little data are available at such magnitudes.

As noted in the introduction, increased streamflow also commonly occurs after earthquakes. After the 2003 San Simeon, California, earthquake, streamflow even appeared in a nearby dry valley where the groundwater table was several tens of meters below the surface (Wang et al., 2004a). Figure 1b shows the distance to the earthquake epicenter from documented postseismic streamflow increases against earthquake magnitude, based on an existing compilation (Montgomery and Manga, 2003) updated with data up to December, 2003 (Wang et al., 2004b). Also plotted is equation (1) for liquefaction, which appears to be a limiting bound for the postseismic streamflow increase too. This may not be surprising since the mechanisms that control earthquake-induced liquefaction(e.g., Terzaghi et al., 1996) can also control earthquake-induced 
streamflow (Manga et al., 2003). Hence, equation (1) will be used to estimate the maximum epicentral distances to both liquefaction and increased streamflow.

For meteoritic impacts, there are too few documented examples of liquefaction to determine the farthest distance to the liquefaction site or the occurrence of increased streamflow. Thus an indirect approach is required. From cratering experiments and dimensional analysis, an empirical $\pi$-scaling relation was derived by Melosh (1989), relating the diameter of the impact crater, $D$, and the impact energy $W_{i m}$ (all parameters in SI units):

$$
D=1.8 \rho_{p}^{0.11} \rho_{t}^{-1 / 3} g_{\text {planet }}{ }^{-0.22} L^{0.13} W_{i m}{ }^{0.22}
$$

where $\rho$ and $\rho$ are, respectively, densities of the projectile and target, $g_{\text {planet }}$ is the surface gravity of the planet, and $L$ is the projectile diameter. Obviously, other combinations of variables are possible, for example, $W_{i m}$ may be expressed in terms of the size, density and velocity of the impactor. We prefer the combination of variables in equation (2) because the impact energy may be related to seismic energy, as explained next, and the crater diameter $D$ is directly observable, while the alternative choice of the impactor size or velocity as variables may not be helpful from an observation or application perspective.

In large impacts, most of the impact energy is spent in fracturing, ejecting, heating, melting and vaporizing the projectile and the target, and only a small part of the impact energy is converted to seismic waves (with energy $W_{s}$ ), with a conversion factor $s=W_{s} / W_{i m}$ known as the seismic efficiency. Estimates of $s$ range from $10^{-5}$ to $10^{-3}$, with the most commonly accepted value being $10^{-4}$ (e.g., Schulz and Gault, 1975). Given $W_{s}$, we may estimate the seismic magnitude produced by an impact by using the classical Gutenberg-Richter relation:

$$
\log W_{s}=4.8+1.5 M_{i m}
$$

Impact-generated seismic events, however, contain significantly less shear energy than earthquakes of the same magnitudes. A rule of thumb developed from cratering experiments is 
that, to produce the same amount of shear energy, the seismic magnitude of an impact needs to be one magnitude greater than that of an earthquake (Melosh, 1989). Replacing $M$ in (1) by $M_{i m}+1$, $W_{s}$ in (3) by $s W_{i m}$, and combining (1) and (3), we obtain

$$
R_{\max }=\left[\frac{s}{c} W_{i m}\right]^{0.3}
$$

where $c=10^{-4.2}$. Furthermore, in applying this relation to different planets, we need to scale it with respect to the surface gravity of the planets, because the occurrence of consolidation and liquefaction requires relative motion among soil particles which is resisted by the friction between soil particles, which in turn is, on the average, proportional to gravity. Since the stress required to overcome friction is, to a first approximation, proportional to strain and hence to the square root of strain energy that in turn is, again to a first approximation, proportional to the inverse square of distance, the liquefaction limit on a planet may be scaled by a factor of $g_{\text {earth }} / g_{\text {planet }}$. Hence the maximum distance from impact on a planet to liquefaction and streamflow increase $\left(R_{\max }\right)$ is related to the crater diameter $(D)$ by

$$
R_{\text {max }}=\frac{g_{\text {earth }}}{g_{\text {planet }}}\left[\frac{s}{c}\left(\frac{D}{1.8 \rho_{p}^{0.11} \rho_{t}^{-1 / 3} g_{\text {planet }}^{-0.22} L^{0.13}}\right)^{\frac{1}{0.22}}\right]^{0.3}
$$

\section{Discussion}

Equation (5) predicts, for Earth (Figure 2a), $R_{\max }=200 \pm 100 \mathrm{~km}$ for the Oasis crater in Lybia $\left(D=11.5 \mathrm{~km}\right.$; Underwood, 1976) and $R_{\max }=5,000 \pm 2000 \mathrm{~km}$ for the Chicxulub crater in Mexico ( $D \sim 100 \mathrm{~km}$; Melosh, 1989). To this group we add the Upheaval Dome crater (Alvarez et al., 1998), with $D=4 \mathrm{~km}$ and $R_{\max }=60 \pm 30 \mathrm{~km}$, even though the origin of this crater is controversial. Figure 2 a shows that the observations at all these sites are consistent with predictions, although there is too little data to constrain $R_{\max }$ as a function of $D$. Also plotted in Figure $2 \mathrm{a}$ is the possible liquefaction-induced debris-flow deposit $\sim 450 \mathrm{~km}$ south of the young 
Lowell crater $(D \sim 250 \mathrm{~km})$ on Mars (Tanaka et al., 1998). This deposit, if correctly explained, is also consistent with prediction.

Based on the liquefaction limit proposed for Mars (Figure 2a), we suggest that impacts producing craters with diameters of $100 \mathrm{~km}$ or greater may have caused global occurrence of liquefaction and streamflow. Assuming the timeline proposed by Frey (2004) for impact events on early Mars, we estimate a total of $\sim 380$ impacts with crater diameter $>200 \mathrm{~km}$ since Hellas formed (4.02 Ga). Assuming further a -2 power law for crater size distribution (Hartmann and Neukum, 2001), we infer a total of $\sim 1,500$ impacts with crater diameter $>100 \mathrm{~km}$ and $\sim 10^{5}$ impacts with crater diameter $>10 \mathrm{~km}$ since Hellas. The liquefaction effect due to each smaller impact, however, decreases drastically according to equation (5). Using this relation and a -2 power law for crater size distribution, we compare the integrated maximum liquefaction area caused by the numerous 'mid-size" impacts (with crater diameters from 10 to $100 \mathrm{~km}$ ) with that caused by the fewer but larger impacts. We find the former is comparable to that caused by impacts with crater diameters from 100 to $200 \mathrm{~km}$, but is smaller by nearly an order of magnitude than that caused by impacts with crater diameters from 100 to $1,000 \mathrm{~km}$.

Soil engineers sometimes assert that the occurrence of liquefaction is limited within the upper few tens of meters of Earth's surface. This conclusion, however, may be a result of limited information. Liquefaction structures ranging from a few hundred to several kilometers in depth have been documented in exploration well logs (Deville et al., 2003), inferred from seismic profiles (Van Rensbergen and Morley, 2003), and from geochemical studies of the extruded liquefied sediments (Deyhle et al., 2003).

The amount of groundwater released from soils during liquefaction may be determined from the change in soil volume (the volumetric strain) which is mostly related to the degree of consolidation of the liquefied soils. Laboratory measurements (Silver and Seed, 1971; Yoshimi and Kuwabara, 1973; Whitman et al., 1981) and field investigation of soil settlement (Lee and Albaisa, 1974) showed that the amount of water released during liquefaction ranges from $3-5 \%$ 
of the soil volume for loose sands and $0.2 \%$ or smaller for very dense sands. As an order-ofmagnitude estimate in the present study, we assume that the amount of groundwater released from the Martian regolith during liquefaction is $1 \%$ of the regolith volume.

As noted earlier, the liquefaction sites at the farthest distance $R_{\max }$ are those with optimal conditions for liquefaction. Observations on Earth show that the actual occurrence of liquefaction is rather spotty and would account only $\sim 1 \%$ of the maximum possible area of $\pi\left(R_{\max }\right)^{2}$. Thus the volume of groundwater released during an impact event from an aquifer of thickness $h$ would be of the order of $10^{-4} \pi\left(R_{\max }\right)^{2} h$. The result for Mars (Figure $2 \mathrm{~b}$ ) shows that impacts that produced craters of $\sim 100 \mathrm{~km}$ in diameter may each have released groundwater with a volume of $\sim 10^{4} \mathrm{~km}^{3}$ from a 1-km thick global aquifer. Using equations (2) and (3) and assuming a seismic efficiency of $10^{-4}$ we estimate that the equivalent seismic magnitude for impacts producing craters of $\sim 100$ $\mathrm{km}$ in diameter is $\sim 10$. Since this is beyond the range of magnitudes for which there is data for liquefaction or streamflow (Figure 1), the application of equation (1) in estimating $R_{\max }$ may be subjected to substantial uncertainty and can only be taken as an order-of-magnitude estimate. Nonetheless, we may reasonably suggest that even greater amounts of groundwater may have been released during impacts that produced the largest basins on Mars (i.e., Hellas, Chryse, Argyre, Isidis, Utopia, with $D \sim 10^{3} \mathrm{~km}$ ).

Estimating the volume of floodwater required to form the outflow channels is difficult. Assuming that the regolith in the outflow channels was removed by a single outburst flood, Carr (1986) estimated a lower bound of $\sim 7 \times 10^{4} \mathrm{~km}^{3}$ for the Maja Valles and $\sim 7 \times 10^{5} \mathrm{~km}^{3}$ for the Kasei Valles. However, the regolith in the outflow channels may have been removed by many separate flood events, each with a much smaller volume of floodwater (e.g., Williams et al., 2000). Thus the amount of groundwater released by impact may be sufficient to form the outflow channels.

A thick cryosphere and hence cold climate on Mars are often thought to be required in the Hesperian for the formation of outflow channels (e.g., Clifford and Parker, 2001). A thick 
cryosphere allows the buildup of pore pressure in the underlying aquifer, thereby enabling violent eruptions of groundwater and formation of large catastrophic floods. In the model presented here, lithostatic pore pressures are created during each liquefaction event by undrained compaction of soils induced by meteoritic impacts. Thus violent eruptions of groundwater and large catastrophic floods in the Hesperian may occur without requiring a thick cryosphere or cold climate. In fact, a thin, and thus a weak, cryosphere may be necessary for the model, since a thicker cryosphere may make it more difficult for groundwater to breakout. Thus the model implies that large releases of groundwater may have declined drastically near the end of the era of heavy bombardment consistent with the dramatic decline of erosion rates during that time (Baker and Patridge, 1986; Craddock and Maxwell, 1993). The model is also consistent with the evidence for massive subsurface flow of water (Carr and Malin, 2000) and localized water sources for the valley networks (Gulick, 2001) because the eruption of pressurized groundwater will be focused in newly formed or pre-existing fractures.

One particular surface manifestation of liquefaction on Mars may be the chaotic terrain (Figure 3a) often found at the heads of outflow channels (Ori and Mosangini, 1998), which is commonly attributed to the collapse of the surface when groundwater is evacuated (e.g., Carr, 1996). However, the checkerboard patterns of gaps between blocks of chaotic terrain (Figure 3a) suggest some combinations of lateral spreading and collapse. Liquefaction on Earth (Figure 3b) often leads to lateral spreading and collapse of the surface (e.g., Kayan et al., 2002), so chaotic terrain on Mars may be a manifestation of the same effect, but on a much larger scale. Lateral spreading creates tensile stresses in the overlying layers, causing rupture to allow groundwater and liquefied sediments to erupt to the surface. The lower gravity on Mars implies lower confining pressure at depths, which in turn implies a reduction in the required pore pressure for rupturing the overlying layers. Water so expelled could then have deepened and widened the fractures between the blocks and carved the outflow channels often associated with chaotic terrains. 
The average block size in Figure $3 \mathrm{a}$ is greater than that in Figure $3 \mathrm{~b}$ by a factor of $\sim 10^{3}$. Assuming that, at the onset of lateral spreading, the integrated tensile stress across an incipient vertical fracture through the block is balanced by the integrated shear stress over the base of the block, the $\sim 10^{3}$ difference between the average block sizes in the two cases implies a $\sim 10^{3}$ difference between the thicknesses of the frozen ground. The frozen ground in Figure $3 \mathrm{~b}$ was 0.3 $\mathrm{m}$ thick (Kayan et al., 2002); this implies that the cryosphere in Figure 3a may have been $\sim 300 \mathrm{~m}$ thick when the chaotic terrain was formed.

The challenge for the future may be to find field evidence that either supports or refutes the above predictions. Geologists gather evidence for paleo-liquefaction on Earth by examining the detailed relations among sedimentary units exposed on cliffs or man-made trenches (e.g., Obermeier, 1996; Warme et al., 1998); thus the task for recognizing paleo-liquefaction on Earth for a particular impact event is limited by the preservation of the sedimentary record. Since erosion rates on Mars are presumably much lower and the crust has undergone far less tectonic activity, the geologic records are likely to be much better preserved on Mars than on Earth. With a long line of planned orbitor, rover and lander missions in the queue, it will be just a matter of time before sufficient geologic evidence is accumulated to test the above hypothesis.

Acknowledgements. This work grew out of a graduate seminar on floods on Mars in the Spring of 2004. We thank the participants of the seminar for discussions and comments, and Sarah Stewart, James Richardson and Jay Melosh for reviewing the manuscript and offering constructive comments that helped to improve the paper. Work is supported by US National Science Foundation (EAR-0125548) and NASA Astrobiology Institute (NNA04CC02A). 


\section{References}

Alvarez, W., E. Staley, D. O'Connor, and M.A. Chan, 1998, Synsedimentary deformation in the Jurassic of southeastern Utah - A case of impact shaking? Geology, 26, 579-582.

Ambraseys, N.N., 1988, Engineering seismology, Earthquake Eng. Structural Dynamics, 17, 1105.

Bralower, T.J., C.K. Paull and R.M. Leckie, 1998, The Cretaceous-Tertiary boundary cocktail: Chicxulub impact triggers margin collapse and extensive sediment gravity flows, Geology, 26, 331-334.

Carr, M.H., 1986, Mars - a water-rich planet, Icarus, 68, 187-216.

Carr, M.H., 1996, Water on Mars, Oxford University Press, New York, 229 pp.

Carr, M.H., and M.C. Malin, 2000, Meter-scale characteristics of Martian channels and valleys, Icarus, $146,366-386$.

Charlie, W.A., G.E. Veyera, D.S. Durnford, D.O. Doehring, 1996, Porewater pressure increases in soil and rock from underground chemical and nuclear explosions, Eng. Geol., 43, 225236.

Clifford, S.M., 1997, The origin of the martian intercrater plains: The role of liquefaction from impact and tectonic-induced seismicity, Lunar Planet. Sci. Conf., 27, 241.

Clifford, S.M., and T.J. Parker, 2001, The evolution of the Martian hydrosphere: Implications for the fate of a primordial ocean and the current state of the northern plains, Icarus, 154, 4079.

Deville, E., A. Battani, R. Griboulard, S. Guerlais, J.P. Herbin, J.P. Houzay, C. Muller, and A. Prinzhofer, 2003, The origin and processes of mud volcanism: new insights from Trinidad, in Subsurface Sediment Mobilization, eds.: P. Van Rensbergen, R.R. Hillis, A.J. Maltman, and C.K. Morley, Geol. Soc. London Sp. Publ. 216, 475-490.

Deyhle, A., A.J. Kopf, and G. Aloisi, 2003, Boron and boron isotopes as tracers for diagenetic reactions and depth of mobilization, using muds and authigenic carbonates from eastern 
Mediterranean mud volcanoes, in Subsurface Sediment Mobilization, eds.: P. Van

Rensbergen, R.R. Hillis, A.J. Maltman, and C.K. Morley, Geol. Soc. London Sp. Publ. 216, 491-503.

Frey, H.V., 2004, A timescale for major events in early Mars crustal evolution, Lunar Planet. Sci. Conf. XXXV Abstract, 1382.

Galli, P., 2000, New empirical relationships between magnitude and distance for liquefaction, Tectonophysics, 324, 169-187.

Gulick, V.C., 2001, Origin of the valley networks on Mars: a hydrological perspective, Geomorphology, 37, 241- 268.

Hartmann, W.K., and G. Neukum, 2001, Cratering chronology and the evolution of Mars, Space Sc. Rev., 96, 165-194.

Kayen, R., E. Thompson, D. Minasian, B. Collins, E.R.S. Moss, N. Sitar, and G. Carver, 2002, Geotechnical reconnaissance of the November 3, 2002 M7.9 Denali fault earthquake, Earthquake Spectra, Special Volume on the M7.9 Denali Earthquake of 3 November $2002,1-27$.

Klaus, A. R.D. Norris, D. Kroon, and J. Smit, 2000, Impact-induced mass wasting at the K-T boundary: Blake Nose, western North Atlantic, Geology, 28, 319-322.

Kuribayashi, E., and F. Tatsuoka, 1975, Brief review of liquefaction during earthquakes in Japan, Soil and Foundations, 15, 81-92.

Leyva, I.A., and S.M. Clifford, 1993, The seismic response of an aquifer to the propagation of an impact generated shock wave: A possible trigger of the martian outflow channels? Lunar Planet. Sci., 24, 875-876.

Melosh, H.J., 1989, Impact Cratering - A Geologic Process, Oxford University Press, New York, $245 \mathrm{pp}$.

Lee, K.L., and A. Albaisa, 1974, Earthquake-induced settlement in saturated sands, J. Soil Mech. Foundations Division, ASCE, 100, 387-406. 
Manga, M., E.E. Brodsky, and M. Boone, 2003, Response of streamflow to multiple earthquakes and implications for the origin of postseismic discharge changes, Geophys. Res. Lett., 30, doi:10.1029/2002GL016618.

Montgomery, D.R., and M. Manga, 2003, Streamflow and water well responses to earthquakes, Science, 300, 2047-2049.

Muir-Wood, R., and G.C.P. King, 1993, Hydrological signatures of earthquake strain: $J$. Geophys. Res., 98, 22035-22068.

Ori, G.G., and C. Mosangini, 1998, Complex depositional systems in Hydrates Chaos, Mars: An example of sedimentary process interactions in the Martian hydrological cycle, $J$. Geophys. Res., 103, 22713-22723.

Rojstaczer, S., S. Wolf, and R. Michel, 1995, Permeability enhancement in the shallow crust as a cause of earthquake-induced hydrological changes, Nature, 373, 237-239.

Schubert, G., S.C. Solomon, D.L. Turcotte, M.J. Drake, and N.H. Sleep, 1992, Origin and thermal evolution of Mars, in H.H. Kieffer et al., eds., Mars, University of Arizona Press, Tucson, 147-183.

Schultz, P.H., and D.E. Gault, 1975, Seismic effects from major basin formation on the moon and Mercury, The Moon, 12, 159-177.

Silver, M.L., and H.B. Seed, 1971, Volume changes in sands during cyclic load, J. Soil Mech. Foundations Division, ASCE, 97, 1171-1182.

Stewart, S.T., T.J. Ahrens, and J.D. O'Keefe, 2003, Impact-induced melting of near-surface water ice on Mars, in M.D. Furnish, ed., 13th APS Topical Confernce on Shock-Compression of Condensed Matter, American Institute of Physics, College Park, MD.

Tanaka, K.L., J.M. Dohm, J.H. Lias, and T.M. Hare, 1998, Erosional valleys in the Thaumasia region of Mars: Hydrothermal and seismic origins, J. Geophys. Res., 103, 31407-31419. 
Terry, D.O., J.A. Chamberlain,P.W. Stoffer, P. Messina, and P.A. Jannett, 2001, Marine Cretaceous-Tertiary boundary section in southwestern South Dakota, Geology, 29, 10551058.

Terzaghi, K., R.B. Peck, and G. Mesri, 1996, Soil Mechanics in Engineering Practice, 3rd edn., John Wiley \& Sons, New York, 549 pp.

Underwood, J.R., 1976, Impact structures of the Libyan Sahara: Some comparisons with Mars, Geol. Romana, 15, 337-340.

Van Rensbergen, P., and C.K. Morley, 2003, Re-evaluation of mobile shale occurrences on seismic sections of the Champion and Baram deltas, offshore Brunei, in Subsurface Sediment Mobilization, eds.: P. Van Rensbergen, R.R. Hillis, A.J. Maltman, and C.K. Morley, Geol. Soc. London Sp. Publ., 216, 395-409.

Waller, R.M., 1968, Water-sediment ejections, in The Great Alaska Earthquake of 1964, Hydrology, National Academy of Science Pub. 1603, Washington, DC, 97-116.

Wang, C.Y., M. Manga, D. Dreger, A. Wong, 2004a, Streamflow increase due to rupturing of hydrothermal reservoirs - Evidence from the 2003 San Simeon, California, earthquake, Geophys. Res. Lett., 31, doi:10.1029/2004GL020124.

Wang, C.Y., C.H. Wang, and M. Manga, 2004b, Coseismic release of water from mountains: Evidence from the $1999(\mathrm{Mw}=7.5)$ Chi-Chi, Taiwan, earthquake, Geology, 32, 769-772.

Warme, J.E., and H.C. Kuehner, 1998, Anatomy of an anomaly: The Devonian catastrophic Alamo impact breccia of southern Nevada, Intern. Geology Rev., 40, 189-216.

Whitman. R.V., P.C. Lambe, abd B.L. Kutter, 1981, Initial results from a stacked ring apparatus for simulation of a soil profile, Proc. Int. Conf. Recent Advances Geothech Engin. Soil Dynamics, 3, St. Louis, 1105-1110.

Williams, R.M., R.J. Phillips, and M.C. Malin, 2000, Flow rates and duration within Kasei Valles, Mars: Implications for the formation of a martian ocean, Geophys. Res. Lett., 27, 1073-1076. 
Yoshimi, Y., and F. Kuwabara, 1973, Effect of subsurface liquefaction on the strength of surface soil, Soils and Foundations, 13, 67-81. 


\section{Figure captions}

Figure 1. (a) Updated compilation of data for epicentral distance, corrected for an average depth of $10 \mathrm{~km}$ for Earthquake sources, to documented liquefaction (circles) versus earthquake magnitude. Labeled curves show various estimates of the liquefaction limit as a function of earthquake magnitude: Solid curve, equation (1) of this study, short dash curve, Ambraseys ${ }^{18}$, long-dash curve, Galli ${ }^{19}$, and dotted curve, Charlie et al. ${ }^{20}$ for underground explosions. (b) Updated compilation of data for epicentral distance, corrected for an average depth of $10 \mathrm{~km}$ for Earthquake sources, to documented streamflow increase (circles) versus earthquake magnitude; curve shows equation (1).

Figure 2. (a) Estimated maximum extent of liquefaction and increased streamflow are plotted versus impact-crater diameter on Earth and Mars: solid line for seismic efficiency of $10^{-4}$ and dashed lines for seismic efficiencies of $10^{-3}$ and $10^{-5}$, respectively. Observations for liquefaction on Earth are plotted in solid circles: Oasis Dome (Underwood, 1976), Chicxulub crater (Terry et al., 2001) and Upheaval Dome (Alvarez et al., 1998); liquefaction-induced landslide related to Chicxulub crater (Klaus et al., 2000) is plotted in inverted triangle. Also plotted is a possible liquefaction-induced debris-flow deposit south of the young Lowell crater (Tanaka et al., 1998). (b) Estimated maximum volume of released groundwater by impactinduced liquefaction as a function of crater diameter for a range of aquifer thickness.

Figure 3. (a) Chaotic terrain on Mars at the heads of outflow channels Simud Vallis and Tiu Vallis (from Ori and Mosangini, 1998). (b) Lateral spreading of frozen ground due to liquefaction of a sand bar on the Tanana River in Alaska after the 2002 Denali earthquake (from Kayen et al., 2002). The polygonal pattern was observed along several hundred $\mathrm{km}$ of the river deposits. 



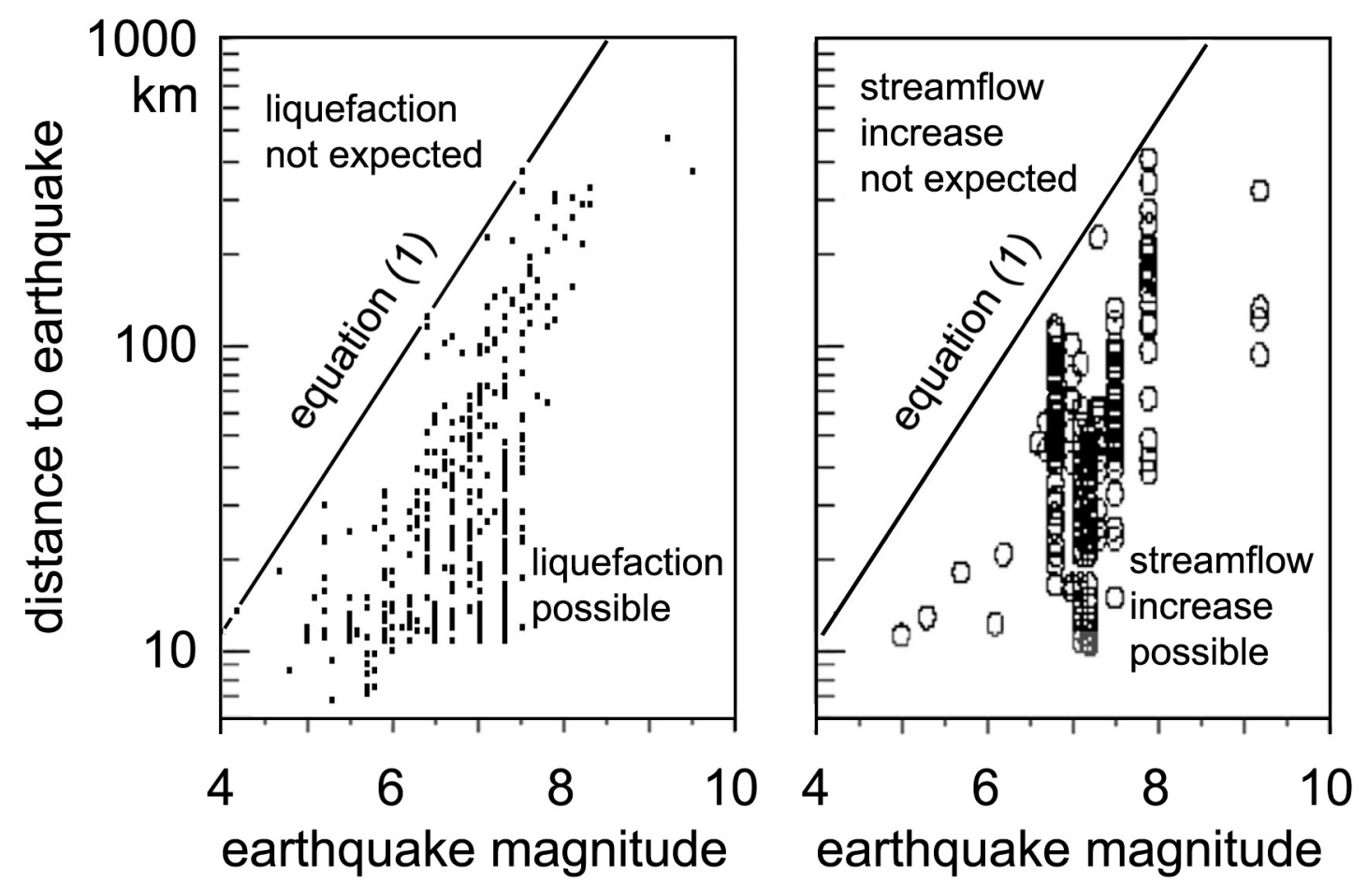



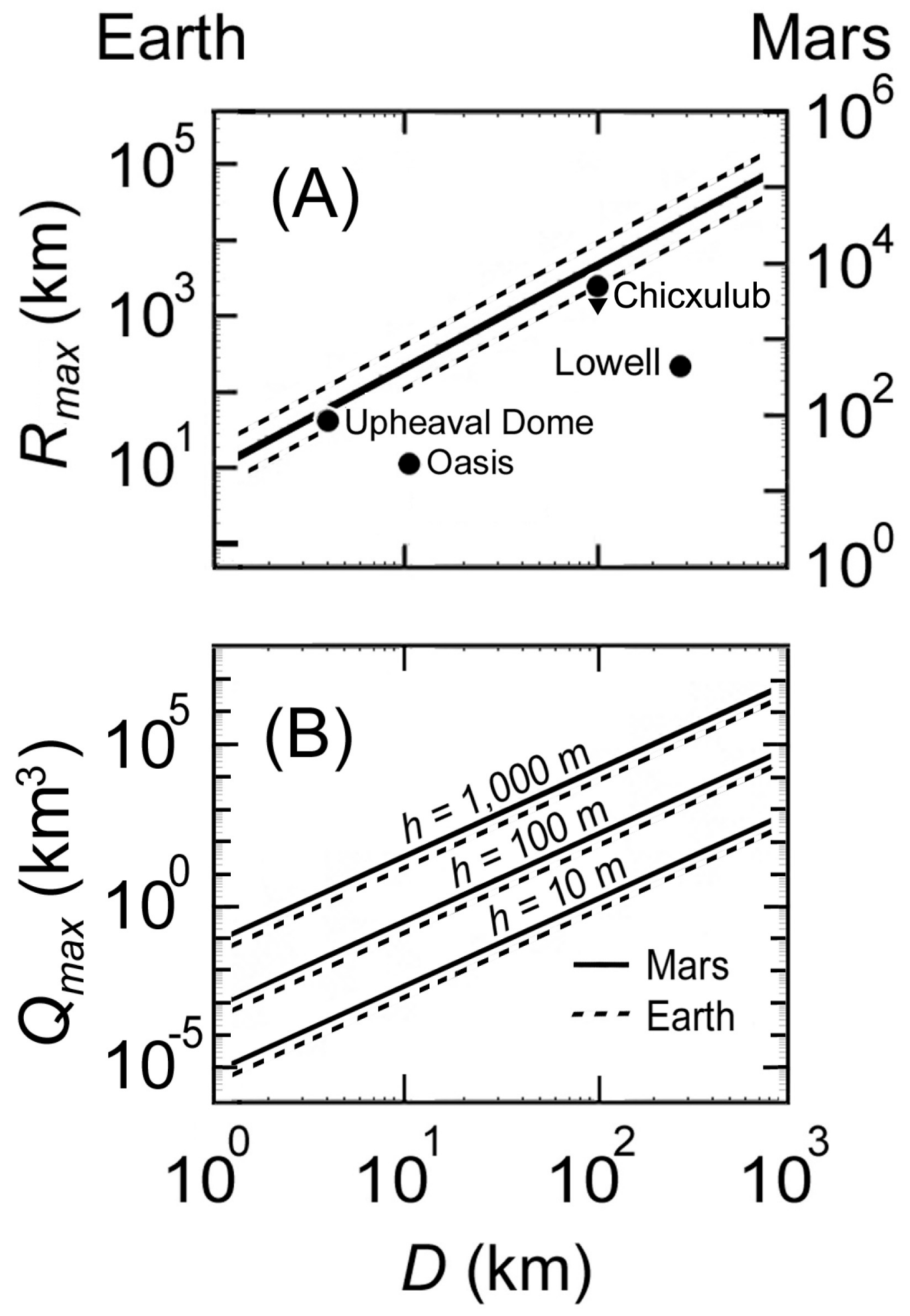

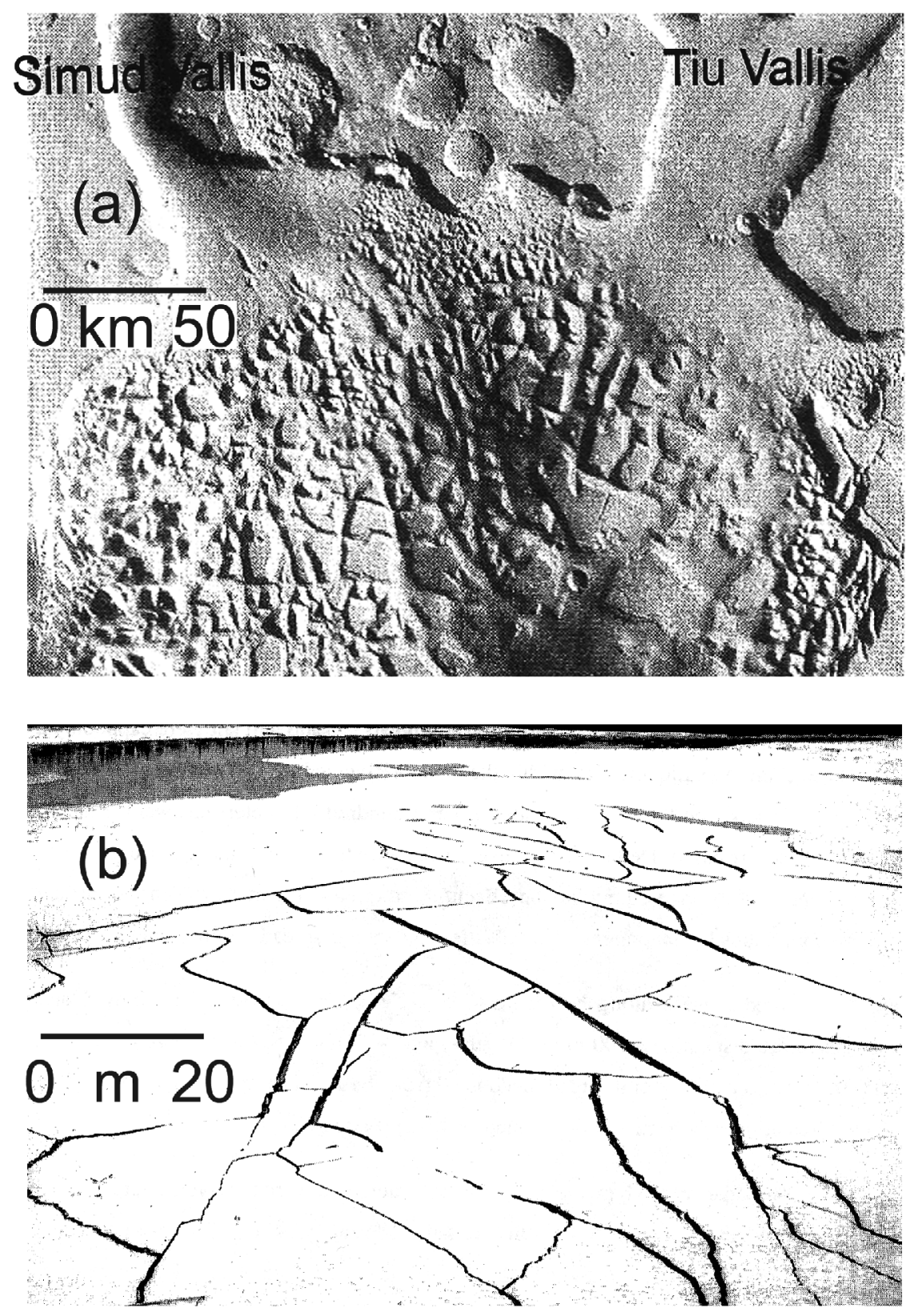
Table 1. Supplemented data for maximum distance to epicenter from documented occurrences of liquefaction and increased streamflow during large earthquakes from 1980 to 2003.

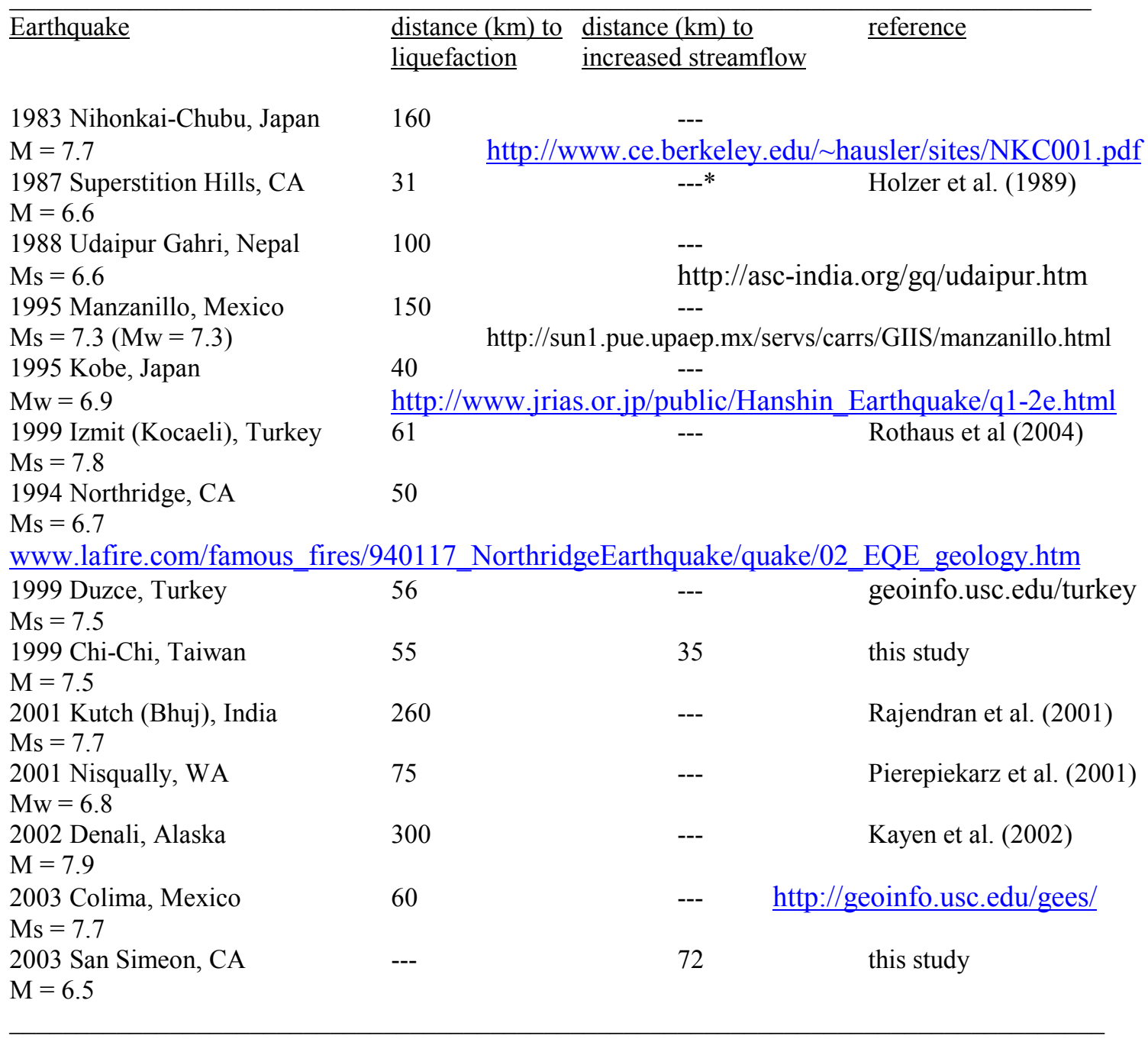

* Dash indicates no documented occurrence known to the authors. 